\title{
3D Mueller-matrix mapping of biological optically anisotropic networks
}

\author{
O.G. Ushenko ${ }^{1}$, V.O. Ushenko ${ }^{1}$, G.B. Bodnar ${ }^{2}$, V.G. Zhytaryuk ${ }^{1}$, O.G. Prydiy ${ }^{1}$, \\ G. Koval' ${ }^{2}$ I. Lukashevych ${ }^{2}$, O.Vanchuliak ${ }^{2}$ \\ ${ }^{1}$ Chernivtsi National University, 2 Kotsiubynskyi St., Chernivtsi, Ukraine, 58012 \\ 2 Bukovinian State Medical University, 3 Theatral Sq., Chernivtsi, Ukraine, 58000
}

\begin{abstract}
The paper consists of two parts. The first part presents short theoretical basics of the method of azimuthally-invariant Mueller-matrix description of optical anisotropy of biological tissues. It was provided experimentally measured coordinate distributions of Mueller-matrix invariants (MMI) of linear and circular birefringences of skeletal muscle tissue. It was defined the values of statistic moments, which characterize the distributions of amplitudes of wavelet coefficients of MMI at different scales of scanning. The second part presents the data of statistic analysis of the distributions of amplitude of wavelet coefficients of the distributions of linear birefringence of myocardium tissue died after the infarction and ischemic heart disease. It was defined the objective criteria of differentiation of the cause of death.
\end{abstract}

Keywords: Mueller matrix, biological layers, diagnostic, interference.

\section{THEORETICAL BASICS AND EXPERIMENTAL REALIZATION OF THE METHOD OF 3D MUELLER-MATRIX MAPPING OF BIOLOGICAL LAYERS}

\subsection{Analytical foundations of 3D Mueller-matrix mapping}

In the set of works ${ }^{1-13}$ it were defined the algorithms and methods of polarimetric and correlation obtaining of the information about 2D distributions of optical anisotropy of biological tissues. As the basis of theoretical description of the method of 3D Mueller-matrix mapping it was used the results obtained in ${ }^{14,15}$. Here, the use of a reference wave of laser radiation, which in the scheme of optical interferometer is superimposed on a polarizationally inhomogeneous image of a biological layer is fundamental. The resulting interference pattern is recorded using a digital camera. With the use of diffraction integrals the operation of digital holographic reproduction of distributions of complex amplitudes $\left\{E_{x}(x, y) ; \quad E_{y}(x, y)\right\}$ of the objective field of a biological layer is performed ${ }^{16}$.

For each state of the irradiating beam, the reconstructed distributions of the Stokes vector parameters of the object field of a biological layer are calculated according to the reproduced distributions of complex amplitudes $\left\{E_{x}(x, y) ; \quad E_{y}(x, y)\right\}$

$$
\left(\begin{array}{l}
S_{1} \\
S_{2} \\
S_{3} \\
S_{4}
\end{array}\right)\left(0^{0}, 90^{0}, 45^{0}, \otimes\right)=\left(\begin{array}{c}
\left|E_{x}\right|^{2}+\left|E_{y}\right|^{2} \\
\left|E_{x}\right|^{2}-\left|E_{y}\right|^{2} \\
2 \operatorname{Re}\left|E_{x} E_{y}^{*}\right| \\
2 \operatorname{Im}\left|E_{x} E_{y}^{*}\right|
\end{array}\right)
$$

Here $0^{0}, 90^{0}, 45^{0}$ - polarization azimuths of linearly polarized irradiating beams, $\otimes$ - the right-circularly polarized beam.

Thirteenth International Conference on Correlation Optics, edited by

Oleg V. Angelsky, Proc. of SPIE Vol. 10612, 1061210 · ( 2018 SPIE

CCC code: 0277-786X/18/\$18 - doi: 10.1117/12.2304736 
Further, on the basis of relations (1), the set of Mueller matrix elements is calculated by the following Stokespolarimetric relations:

- for Stokes vectors of linearly polarized probing beams $S^{0}\left(0^{0}\right), S^{0}\left(90^{0}\right)$ :

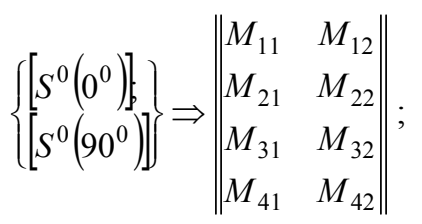

- for Stokes vectors of linearly polarized probing beams $S^{0}\left(45^{0}\right) ; S^{0}\left(135^{0}\right)$ :

$$
\left\{\left[S^{0}\left(45^{0}\right)\right] ;\right\},\left\|\begin{array}{ll}
M_{11} & M_{13} \\
M_{21} & M_{23} \\
S_{31} & M_{33} \\
M_{41} & \left.M_{43}\right)
\end{array}\right\| ;
$$

- For Stokes vectors of right- and left-circularly polarized probing beams $S^{0}(\otimes) ; \quad S^{0}(\oplus)$ :

$$
\left\{\left[S^{0}(\otimes)\right\}\right],\left|\begin{array}{ll}
M_{11} & M_{14} \\
M_{21} & M_{24} \\
M_{31} & M_{34} \\
M_{41} & M_{44}
\end{array}\right| \text {; }
$$

Therefore, the direct Muller-matrix mapping results in two-dimensional distributions of the values of matrix elements $M_{i k}=q_{j}\left(S_{z=1 ; 2 ; 3 ; 4}(x, y, \delta)\right)$, averaging $(\delta(z=l))$ over the entire thickness $l$ of the biological layer.

In the case of using a coherent reference wave and algorithms of digital holographic reproduction ${ }^{14,15}$ it is possible to reconstruct the distributions of complex amplitudes $\left|E_{x}\right| \exp i\left(\Delta \delta_{x}\right) ; \quad\left|E_{y}\right| \exp i\left(\Delta \delta_{y}\right)$ of the object field in a discrete $\left(\Delta \delta_{l=0 \ldots q}\right)$ set of phase planes $\delta_{j}=\left(\begin{array}{c}0 \\ \Delta \delta \\ 2 \Delta \delta \\ \cdot \\ \dot{\delta}\end{array}\right)$. Due to this, one can obtain a set of layer-by-layer distributions of the values of matrix elements $(x, y, k \Delta \delta)$ and determine their volumetric structure

$$
\left.M_{i k}=\left\{g_{s}\left(\left|E_{x}\right|,\left|E_{y}\right|, \delta^{*}\right)\right\} x, y,\left(\begin{array}{c}
0 \\
\Delta \delta \\
\cdot \\
\delta
\end{array}\right)\right) .
$$

As the information Mueller-matrix parameters we have used the azimuthal invariants. The analysis of Muellermatrix invariants (MMI), which is given in $^{17-31}$, revealed their individual "informational" load. Thus, the MMIs $M_{44}$, 
$\Delta M=\frac{M_{32}-M_{23}}{M_{22}+M_{33}}$ values are predominantly determined by the parameters of phase anisotropy - phase shifts between the orthogonal linearly and $(\varphi)$ and circularly $(\theta)$ polarized components of the amplitudes of laser radiation

$$
\left\{M_{44} \sim \cos \varphi ; \Delta M \sim \operatorname{tg} \theta\right.
$$

\subsection{Experimental results of the method of biological layers birefringence mapping}

As the test object we have used the histological section of skin derma. The main anisotropic structures of such objects are the collagen fibrils with linear and circular birefringence. The values of such parameters of optical anisotropy are most adequately described by MMI $M_{44}$ and $\Delta M$ (relation (6)) ${ }^{1-3}$.

Fig. 1 presents the 3D distributions of MMI $M_{44}(x, y, \delta)$ of linear birefringence of histological section of skin derma. Here presented are the following phase sections (relation (5)) $\delta_{j}=\delta$ (fragment (1)); $\delta_{j}=0.7 \delta$ (fragment (2)); $\delta_{j}=0.4 \delta$ (fragment (3)); $\delta_{j}=0.1 \delta$ (fragment (4)).
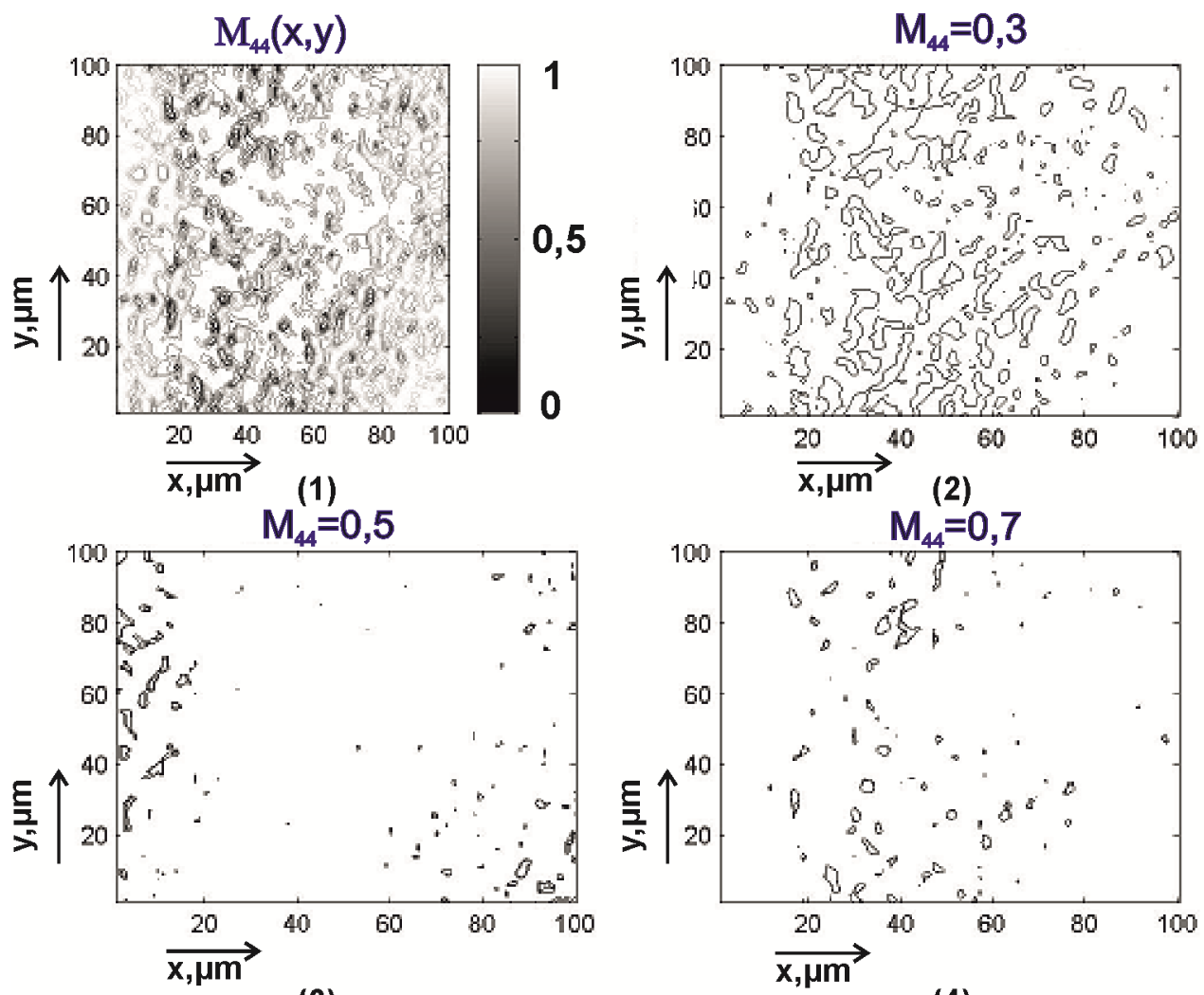

(3)

(4)

Fig. 1. Phase sections of 3D distributions of MMI $M_{44}(x, y, \delta)$ of linear birefringence of the histological section of skin derma: $\delta_{j}=\delta$ (fragment (1)); $\delta_{j}=0.7 \delta$ (fragment (2)); $\delta_{j}=0.4 \delta$ (fragment (3)); $\delta_{j}=0.1 \delta$ (fragment (4)).

In Fig. 2 it was presented the 3D distributions of MMI $\Delta M(x, y, \delta)$ of circular birefringence of the histological section of skin derma. Here presented the following phase sections (relation (5)) $\delta_{j}=\delta$ (fragment (1)); $\delta_{j}=0.7 \delta$ (fragment (2)); $\delta_{j}=0.4 \delta$ (fragment (3)); $\delta_{j}=0.1 \delta$ (fragment (4)). 

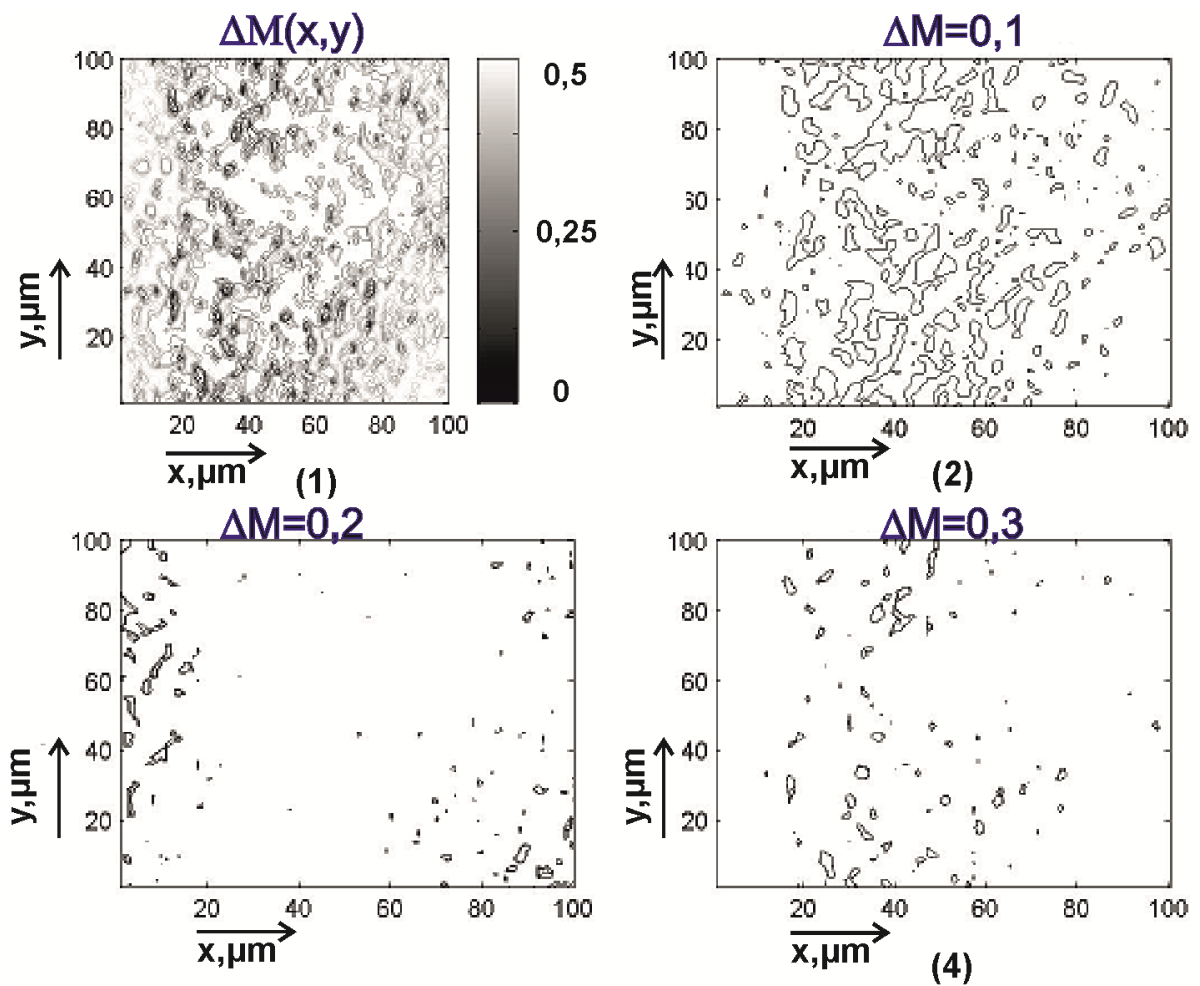

Fig. 2. Phase sections of 3D distributions of MMI $\Delta M(x, y, \delta)$ of circular birefringence of the histological section of skin derma: $\delta_{j}=\delta$ (fragment (1)); $\delta_{j}=0.7 \delta$ (fragment (2)); $\delta_{j}=0.4 \delta$ (fragment (3)); $\delta_{j}=0.1 \delta$ (fragment (4)).

Table 1 presents the results of statistic analysis (statistical moments of the 1 st -4 th orders $Z_{i=1 ; 2 ; 3 ; 4}$ ) of coordinate distributions MMI of the histological section of skin derma in the set of phase sections (relation (5)).

Table 1. Statistical moments $Z_{i=1 ; 2 ; 3 ; 4}$ of the distributions MMI of skin derma anisotropy

\begin{tabular}{|c|c|c|c|c|c|c|c|c|}
\hline$Z_{i=1 ; 2 ; 3 ; 4}$ & \multicolumn{5}{|c|}{$M_{44}$} & \multicolumn{5}{c|}{$\Delta M$} \\
\hline$\delta$ & $\delta$ & $0.7 \delta$ & $0.4 \delta$ & $0.1 \delta$ & $\delta$ & $0.7 \delta$ & $0.4 \delta$ & $0.1 \delta$ \\
\hline$Z_{i=1}$ & 0.47 & 0,21 & 0.36 & 0.15 & 0.27 & 0.21 & 0.12 & 0.09 \\
\hline$Z_{i=2}$ & 0,21 & 0,14 & 0.17 & 0.11 & 0.14 & 0.11 & 0.13 & 0.103 \\
\hline$Z_{i=3}$ & 0,56 & 0.77 & 1.24 & 1.58 & 0.85 & 0.97 & 1.66 & 2.15 \\
\hline$Z_{i=4}$ & 0,43 & 0.92 & 1.48 & 2.02 & 0.74 & 1.19 & 1.78 & 2.42 \\
\hline
\end{tabular}

Individual sensitivity of the value $Z_{i=1 ; 2 ; 3 ; 4}$ to the features of the coordinate distributions of MMI of linear and cirrus birefringence of the skin dermis layer was established. The most optimal were (grayed out) the following phase sections - $M_{44}(0.4 \delta)$ и $\Delta M(0.7 \delta)$.

This fact was using in the basis of applied biomedical use of statistical analysis of coordinate distributions of linear birefringence. 


\section{CLINICAL APPLICATION OF 3D MUELLER-MATRIX MAPPING OF BIREFRINGENCE IN DIFFERENTIAL DIAGNOSTICS OF ENDOMETRIOSIS}

\subsection{Objects of investigation}

Two groups of samples of histological sections of biopsy of uterus:

- $\quad$ endometriosis of the 1 degree - group 1 (32 samples);

- endometriosis of the 2 degree - group 2 (32 samples);.

Histological sections were produced due to the standard technique on the freezing microtome.

\subsection{Experimental results}

Fig. 3 presents the results of 3D mapping of the MMI distributions of linear (fragments (1),(2)) and circular (fragments (3),(4)) birefringences of the histological sections of the uterus biopsy with endometriosis 1 (fragments (1),(3)) and 2 (fragments (2),(4)) in the following sections - $M_{44}(0.4 \delta)$ and $\Delta M(0.7 \delta)$.
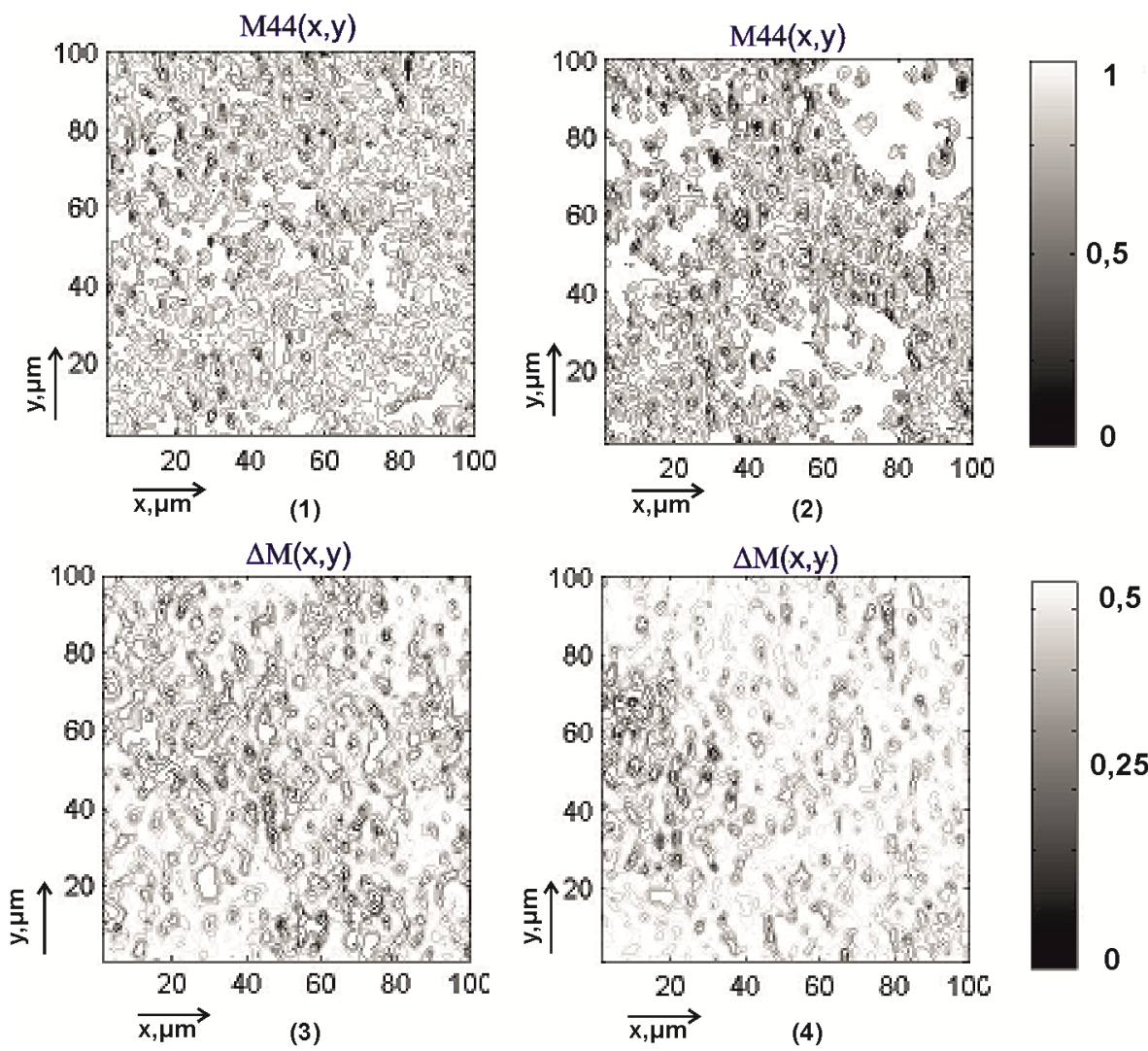

Fig. 3. The results of 3D mapping of the MMI distributions of linear (fragments (1),(2)) and circular (fragments (3),(4)) birefringences of the histological sections of the uterus biopsy with endometriosis 1 (fragments (1),(3)) and 2 (fragments (2),(4)) in the following sections - $M_{44}(0.4 \delta)$ and $\Delta M(0.7 \delta)$.

For the possible clinical application of the Mueller matrix mapping method for each group of samples the operating characteristics, typical for evidence-based medicine ${ }^{32-34}$ that determine the diagnostic power of the method are determined, namely - sensitivity $\left(S e=\frac{a}{a+b} 100 \%\right)$, specificity $\left(S p=\frac{c}{c+d} 100 \%\right)$ and balanced accuracy 
$\left(A c=\frac{S e+S p}{2}\right.$ ), where $a$ and $b-$ the number of correct and incorrect diagnoses within group $2 ; c$ and $d$ - the same within group 1 - Table 2.

Table 2. Balanced accuracy of the method of 3D mapping of the distributions of linear and circular birefringence.

\begin{tabular}{|c|c|c|}
\hline$A c, \%$ & $M_{44}(0.4 \delta)$ & $\Delta M(0.7 \delta)$ \\
\hline$Z_{i=1}$ & $73 \%$ & $69 \%$ \\
\hline$Z_{i=2}$ & $76 \%$ & $74 \%$ \\
\hline$Z_{i=3}$ & $93 \%$ & $82 \%$ \\
\hline$Z_{i=4}$ & $96 \%$ & $84 \%$ \\
\hline
\end{tabular}

It was reached a good $(A c(\Delta M)=82 \%-84 \%)$ and excellent $\left(A c\left(M_{44}\right)=93 \%-96 \%\right)$ level of balanced accuracy of the method of phase sections of 3D Mueller-matrix images of linear and circular birefringence of the histological sections of uterus in differentiation of the severity degree of endometriosis.

\section{CONCLUSIONS}

Short theoretical basics of the method of azimuthally-invariant 3D Mueller-matrix mapping of polycrystalline structure of the distributions of parameters of linear and circular birefringence of biological layers polycrystalline structure were provided. It was demonstrated the results of experimental approbation of such method and defined the distributions of Mueller-matrix invariants in the set of phase sections of linear and circular birefringence of the endometrium histological section. The differentiation of linear and circular birefringence of endometrium with different severity degree was realized. It was reached a good and excellent levels of balanced accuracy of differentiation of endometriosis severity degree.

\section{REFERENCES}

[1] Alexander G. Ushenko and Vasilii P. Pishak, "Laser Polarimetry of Biological Tissue: Principles and Applications", in Handbook of Coherent-Domain Optical Methods: Biomedical Diagnostics, Environmental and Material Science, vol. I, Valery V. Tuchin, Ed. Boston: Kluwer Academic Publishers, 2004, pp. 93-138.

[2] Angelsky, O. V., Bekshaev, A. Ya., Maksimyak, P. P., Maksimyak, A. P., Hanson, S. G., Zenkova, C. Yu., "Self-diffraction of continuous laser radiation in a disperse medium with absorbing particles," Optics Express 21(7), 8922-8938 (2013).

[3] Y. A. Ushenko, T. M. Boychuk, V. T. Bachynsky, O. P. Mincer, "Diagnostics of Structure and Physiological State of Birefringent Biological Tissues: Statistical, Correlation and Topological Approaches" in Handbook of Coherent-Domain Optical Methods, Springer Science+Business Media, p. 107, New York (2013).

[4] V.V. Tuchin, Tissue Optics: Light Scattering Methods and Instruments for Medical Diagnosis, second edition, SPIE Press, Bellingham, WA, PM 166, 2007.

[5] S. Bickel, W. M. Bailey, Stokes vectors, Mueller matrices, and polarization of scattered light, Am. J. Phys. 53 (1985) 468-478.

[6] X. Wang, G. Yao, L., H. Wang, Monte Carlo model and single-scattering approximation of polarized light propagation in turbid media containing glucose, Appl. Opt. 41 (2002) 792-801.

[7] X. Wang, L. - H. Wang, Propagation of polarized light in birefringent turbid media: a Monte Carlo study, J. Biomed. Opt. 7 (2002) 279-290.

[8] Angelsky, O.V., Bekshaev, A. Ya., Maksimyak, P. P., Maksimyak, A. P., Hanson, S.G. ,Zenkova, C. Yu., "Selfaction of continuous laser radiation and Pearcey diffraction in a water suspension with light-absorbing particles," Optics Express 22(3), 2267-2277 (2014).

[9] Angelsky, O. V., Bekshaev, A. Ya., Maksimyak, P. P., Maksimyak, A. P., Hanson, S. G., "Measurement of small light absorption in microparticles by means of optically induced rotation," Optics Express 23(6), 71527163 (2015). 
[10] Polyanskii, V.K., Angelsky, O.V., Polyanskii, P.V., "Scattering-induced spectral changes as a singular optical effect," Optica Applicata 32 (4), 843-848 (2002).

[11] Angelsky, O.V., Besaha, R.N., Mokhun, A.I., Mokhun, I.I., Sopin, M.O., Soskin, M.S., "Singularities in vectoral fields," Proc. SPIE 3904, 40-54 (1999).

[12] Angelsky, O.V., Tomka, Y.Y., Ushenko, A.G., Ushenko, Y.G., Yermolenko, S.B., "2-D tomography of biotissue images in pre-clinic diagnostics of their pre-cancer states," Proc. SPIE 5972, 158-162 (2005).

[13] Angel'skiǔ, O.V., Ushenko, A.G., Ermolenko, S.B.,Ushenko, Yu.A., Pishak, O.V., "Polarization Based Visualization of Multifractal Structures for the Diagnostics of Pathological Changes in Biological Tissues," Optics and Spectroscopy (English translation of Optika i Spektroskopiya) 89 (5), 799-804 (2000).

[14] D. K. Kasaragod et al., "Experimental validation of an extended Jones matrix calculus model to study the 3D structural orientation of the collagen fibers in articular cartilage using polarization-sensitive optical coherence tomography," Biomed. Opt. Express 3(3), 378-387 (2012).

[15] Y. Yasuno et al., "Jones Matrix based polarization sensitive optical coherence tomography," in Optical Coherence Tomography: Technology and Applications, 2nd ed., W. Drexler and J. G. Fujimoto, Eds., pp. 11371162, Springer Reference, Science + Business Media, New York (2015)

[16] J. Tervo, T. Setala, A. Friberg, "Degree of coherence for electromagnetic fields," Opt. Express 11, 1137-1143 (2003).

[17] Yu.A. Ushenko, V.A. Ushenko, A.V. Dubolazov, V.O. Balanetskaya, N.I. Zabolotna, "Mueller-matrix diagnostics of optical properties of polycrystalline networks of human blood plasma," Optics and Spectroscopy 112, 884-892 (2012) .

[18] V.A. Ushenko, O.V. Dubolazov, A.O. Karachevtsev, "Two wavelength Mueller matrix reconstruction of blood plasma films polycrystalline structure in diagnostics of breast cancer," Appl. Opt. 53, B128-B139 (2014).

[19] Y.A. Ushenko, G.D. Koval, A.G. Ushenko, O.V. Dubolazov, V.A. Ushenko, O.Yu. Novakovskaia, "Muellermatrix of laser-induced autofluorescence of polycrystalline films of dried peritoneal fluid in diagnostics of endometriosis," J. Biomed. Opt. 21(7), 071116 (2016).

[20] A.G. Ushenko, A.V. Dubolazov, V.A. Ushenko, O.Y. Novakovskaya, "Statistical analysis of polarizationinhomogeneous fourier spectra of laser radiation scattered by human skin in the tasks of differentiation of benign and malignant formations," J. Biomed. Opt. 21(7), 071110 (2016).

[21] V.P. Prysyazhnyuk, Yu.A. Ushenko, A.V. Dubolazov, A.G. Ushenko, V.A. Ushenko, "Polarization-dependent laser autofluorescence of the polycrystalline networks of blood plasma films in the task of liver pathology differentiation," Appl. Opt. 55, B126-B132 (2016).

[22] Angelskaya, A.O., Gruia, I., Yermolenko, S.B., Ivashko, P.V., Gruia, M.I., "Manifestations of linear dichroism changes in cancer biotissues," Romanian Reports in Physics, 65 (3), 1052-1062 (2013).

[23] Mikhailova, A.D., Yermolenko, S.B., Zimnyakov, D.A., Angelsky, O.V., "Aging-Caused Changes in Optical Anisotropy of Fibrous Tissues," Proc.SPIE, 7388, 738819-1-738819-8 (2009).

[24] V. A. Ushenko, N. I. Zabolotna, S. V. Pavlov, D. M. Burcovets, O. Yu. Novakovska, "Mueller-matrices polarization selection of two-dimensional linear and circular birefringence images," Proc.SPIE 9066, (2013).

[25] V. A. Ushenko, A. V. Dubolazov, "Correlation and self similarity structure of polycrystalline network biological layers Mueller matrices images,” Proc. SPIE 8856, (2013).

[26] Yu. A. Ushenko, V. A. Ushenko, A. V. Dubolazov, V. O. Balanetskaya, N. I. Zabolotna, "Mueller-matrix diagnostics of optical properties of polycrystalline networks of human blood plasma," Optics and Spectroscopy 112(6), 884-892 (2012).

[27] Yu. A. Ushenko, A. V. Dubolazov, V. O. Balanetskaya, A. O. Karachevtsev, V. A. Ushenko, "Wavelet-analysis of polarization maps of human blood plasma," Optics and Spectroscopy 113(3), 332-343 (2012).

[28] V. O. Ushenko "Spatial-frequency polarization phasometry of biological polycrystalline networks," Optical Memory and Neural Networks 22(1), 56-64 (2013).

[29] V. A. Ushenko, N. D. Pavlyukovich, L. Trifonyuk, "Spatial-Frequency Azimuthally Stable Cartography of Biological Polycrystalline Networks," International Journal of Optics 2013, 7 (2013).

[30] Angelsky, O.V., Yermolenko, S.B., Zenkova, C.Yu., Angelskaya, A.O., "Polarization manifestations of correlation (intrinsic coherence) of optical fields," Appl. Opt. 47, 5492-5499 (2008).

[31] V. A. Ushenko, O. V. Dubolazov, A. O. Karachevtsev, "Two wavelength Mueller matrix reconstruction of blood plasma films polycrystalline structure in diagnostics of breast cancer," Applied Optics 53(10), B128-B139 (2014). 
[32] L. Cassidy, "Basic concepts of statistical analysis for surgical research," Journal of Surgical Research 128, 199206 (2005).

[33] C. S. Davis, "Statistical methods of the analysis of repeated measurements," New York: Springer-Verlag, 744, (2002).

[34] A. Petrie, B. Sabin, "Medical Statistics at a Glance," Blackwell Publishing, 157, (2005). 